\title{
Períodos de estratificação na germinação de sementes de alface (Lactuca sativa L.) sob diferentes condições de luz e temperatura
}

\section{Stratification periods in seeds germination of lettuce (Lactuca sativa L.) under different conditions of light and temperature}

\author{
Jennifer Bufalo ${ }^{1 *}$; Amanda Cristina Esteves Amaro ${ }^{2}$; \\ Humberto Sampaio de Araújo ${ }^{3}$; Jaqueline Malagutti Corsato ${ }^{1}$; \\ Elizabeth Orika Ono ${ }^{4}$; Gisela Ferreira ${ }^{4}$; João Domingos Rodrigues ${ }^{4}$
}

\section{Resumo}

\begin{abstract}
As sementes de alface apresentam grande sensibilidade às variações na umidade e temperatura do meio onde germinam e, por isso, estudos com o intuito de melhorar a porcentagem de germinação e o desempenho fisiológico dessas têm sido realizados. Dessa maneira, o trabalho teve como objetivo avaliar a eficiência do tratamento pré-germinativo de estratificação $\left(5^{\circ} \mathrm{C}\right)$ por diferentes períodos, na uniformização e incremento da germinação de sementes de alface submetidas à diferentes condições de luz e temperaturas de germinação. Para a realização do tratamento pré-germinativo, as sementes de alface (Lactuca sativa L.) var. Grandes Lagos Americana foram acondicionadas em caixas plásticas escuras do tipo 'gerbox' e submetidas a estratificação à temperatura de $5^{\circ} \mathrm{C}$, na ausência de luz, por 0,4 , 8, 12 e 16 horas. Após as sementes foram submetidas ao teste de germinação, em caixas plásticas tipo 'gerbox' transparente (luz constante) e escura (ausência de luz), mantidas em câmara de germinação do tipo B.O.D com luz constante nas temperaturas de $20,25,30$ e $35^{\circ} \mathrm{C}$. O delineamento foi inteiramente casualizado, com quatro repetições em esquema fatorial $5 \times 4 \times 2$, cinco períodos de estratificação, quatro temperaturas de germinação e duas condições de luz. A estratificação por 16 horas e as temperaturas de $20^{\circ} \mathrm{C}$ e $25^{\circ} \mathrm{C}$ estimularam a germinação das sementes de alface, propiciando maior porcentagem de germinação, índice de velocidade de germinação e menor tempo médio de germinação. A presença da luz resultou em maior germinação nos períodos de $0,4,8$ e 12 horas de estratificação.
\end{abstract}

Palavras-chave: Lactuca sativa L., luz, temperatura

\begin{abstract}
Lettuce seeds have a high sensitivity to variations in humidity and temperature of the environment where they germinate, therefore, studies with the aim of improve the germination and physiological performance of these have been conducted. Thus, the study aimed to evaluate the efficiency of pregermination treatment stratification $\left(5^{\circ} \mathrm{C}\right)$ for different periods, and increase the uniformity of germination of lettuce seeds submitted to different conditions of light and germination temperatures. In the pre-germinative treatment, the seeds of lettuce (Lactuca sativa L.) var. American Great Lakes were placed in plastic boxes dark of the type "gerbox" and subjected to temperature stratification of 5 ${ }^{\circ} \mathrm{C}$ and the dark for $0,4,8,12$ and 16 hours. After periods of stratification the seeds were submitted to
\end{abstract}

\footnotetext{
1 Bióloga(s), Doutoranda em Ciências Biológicas - Botânica, Instituto de Biociências, Universidade Estadual Paulista "Júlio de Mesquita Filho”, UNESP, Campus Botucatu, SP. E-mail: jenniferbufalo@yahoo.com.br; jaque_corsato@hotmail.com

2 Bióloga, Doutoranda em Agronomia - Horticultura, Faculdade de Ciências Agronômicas, UNESP, Campus Botucatu, SP. E-mail: amandaamaro@uol.com.br

3 Eng $^{\circ}$ Agr $^{\circ}$, Pesquisador Científico APTA, Pólo Alta Sorocabana, Presidente Prudente, SP. E-mail: humbertosaraujo@yahoo.com. br

4 Profs. do Dept ${ }^{\circ}$ de Botânica, Instituto de Biociências, UNESP, Campus Botucatu, SP. E-mail: eoono@ibb.unesp.br; gisela@ibb. unesp.br; mingo@ibb.unesp.br

Autor para correspondência
} 
germination tests which were transferred to plastic boxes type "gerbox" transparent (constant light) and dark (no light) and were maintained in a germination chamber B.O.D with light constant at temperatures of $20,25,30$ and $35^{\circ} \mathrm{C}$. The design used was the entirely randomized with four repetitions, in a factorial outline $5 \times 4 \times 2$, five pre-germinative treatments, four germination temperatures and two light conditions. Stratification for 16 hours and temperatures of 20 and $25^{\circ} \mathrm{C}$ stimulated the germination of lettuce seeds, providing a higher germination percentage, germination speed index and minor mean germination time. The presence of light resulted in increased germination at $0,4,8$ and 12 hours of stratification.

Key words: Lactuca sativa, light, temperature

\section{Introdução}

A alface (Lactuca sativa L.) é uma planta herbácea anual pertencente a família Compositae, que é uma das maiores famílias e apresenta diversas plantas com flores (BOO et al., 2011). A alface é considerada a hortaliça folhosa mais importante na alimentação dos brasileiros e sua propagação é feita por meio de sementes, as quais apresentam particular sensibilidade às variações na umidade e temperatura do meio onde germinam (BERTAGNOLLI et al., 2003).

A temperatura é um fator primário que regula a germinação das sementes diretamente, por meio da ação sobre a própria germinação, ou indiretamente, afetando a dormência e a viabilidade (DENG; SONG, 2012). A temperatura ótima para a germinação das sementes de alface é de $20^{\circ} \mathrm{C}$ e a maioria das cultivares não germinam em temperaturas superiores à $30^{\circ} \mathrm{C}$, isso porque a origem da alface é de regiões de clima temperado, sul da Europa e Ásia Ocidental (FILGUEIRA, 2003; NASCIMENTO; PEREIRA 2007).

Quando ocorrem condições de altas temperaturas durante a embebição das sementes de alface, podem ser observados dois fenômenos: a termoinibição, que é um processo reversível, uma vez que a germinação ocorre quando a temperatura é reduzida para um nível adequado e a termodormência, onde as sementes não germinarão após a redução da temperatura, que representa uma das modalidades de dormência secundária (KHAN, 1980/81; NASCIMENTO; PEREIRA, 2007).

A termoinibição desempenha papel ecologicamente importante para descobrir a época adequada para a germinação de sementes de plantas no inverno e, frequentemente, este fenômeno causa o atraso da germinação de culturas agrícolas, flores e vegetais que possuem como ótimas temperaturas baixas para germinação de suas sementes (DENG; SONG, 2012). Dependendo da variedade, sementes de alface podem apresentar termoinibição e não germinam no escuro e na luz, em temperatura de $26^{\circ} \mathrm{C}$ ou em temperaturas acima desta (BLACK; BEWLEY; HALMER, 2006). A inibição momentânea pode ser eliminada e as sementes podem voltar a germinar após retornarem à temperatura adequada (COONS; KEUHL; SIMONS, 1990).

No Brasil, temperaturas acima de $30^{\circ} \mathrm{C}$ são facilmente encontradas no verão em muitas regiões do país, assim, estudos referentes à adequação de manejo das culturas às condições regionais são práticas indispensáveis para o sucesso do cultivo.

Vários métodos para reduzir o problema da termoinibição têm sido propostos, incluindo a utilização de germoplasmas tolerantes, ajuste do ambiente de produção de sementes, utilização de reguladores vegetais e condicionamento osmótico das sementes. Nestas metodologias, o mecanismo de ação pode estar relacionado com o "enfraquecimento" e "amolecimento" do endosperma, que possibilita o crescimento do embrião sob altas temperaturas (NASCIMENTO; CANTLIFFE, 2002).

As primeiras horas de embebição de água pelas sementes de alface são as mais críticas e deve ocorrer sob temperaturas mais amenas. Portanto, a probabilidade de ocorrer aumento na germinação será sempre maior nas sementes embebidas sob baixas temperaturas do que naquelas embebidas sob altas temperaturas (NASCIMENTO, 2002). 
Ao longo do tempo vários estudos sobre os efeitos de altas temperaturas na germinação de sementes de alface têm sido reportados (BORTHWICK; ROBBINS, 1928). Diferentes hipóteses foram enunciadas como causas da não germinação das sementes de alface, como a redução da permeabilidade do tegumento às trocas gasosas (BORTHWICK; ROBBINS, 1928), a impermeabilidade do tegumento à água (SPEER, 1974), o acúmulo de metabólitos no endosperma e embrião (BORTHWICK; ROBBINS, 1928), efeitos inibitórios do ácido abscísico (McWHA, 1976), mau funcionamento do fitocromo (SCHEIBE; LANG, 1969), barreira física do tegumento e, ou endosperma, inibição da secreção de enzimas da parede celular (IKUMA; TILMANN, 1963) e deficiência do potencial de crescimento do embrião (NABORS; LANG, 1971).

Alguns estudos têm sido realizados com o intuito de melhorar a porcentagem de germinação e expressar melhor o desempenho das sementes de alface. De acordo com Warren e Bennett (1997), muitos são os tratamentos pré-germinativos usados em sementes para incrementar a germinação e melhorar a uniformidade de emergência. A estratificação é um tratamento utilizado para superação da dormência, tornando as sementes metabolicamente ativas e aptas para iniciarem a germinação (CHALFUN; HOFFMANN, 1997). A estratificação desencadeia mecanismos internos modificando a natureza e o nível de hormônios promotores e inibidores envolvidos no controle do processo de dormência na germinação de sementes (CAMPANA et al., 1993; WAGNER JUNIOR et al., 2007). As temperaturas normalmente empregadas na estratificação situamse entre 2 e $7^{\circ} \mathrm{C}$ (POPINIGIS, 1985).

Uma técnica que pode ser recomendada a produtores de alface de regiões quentes é a prégerminação de sementes de alface em baixas temperaturas. Assim, o objetivo do trabalho foi avaliar a eficiência do tratamento pré-germinativo de estratificação $\left(5^{\circ} \mathrm{C}\right)$ por diferentes períodos, na uniformização e incremento da germinação de sementes de alface submetidas à diferentes condições de luz e temperaturas de germinação.

\section{Material e Métodos}

O trabalho foi realizado no Laboratório de Germinação de Sementes do Departamento de Botânica do Instituto de Biociências da Universidade Estadual Paulista (UNESP), Campus de Botucatu, SP. As sementes de alface (Lactuca sativa L.) var. Grandes Lagos Americana utilizadas no estudo foram obtidas comercialmente e o experimento foi dividido em duas etapas, sendo estas descritas à seguir.

Para a realização do tratamento pré-germinativo, as sementes de alface foram acondicionadas em caixas plásticas escuras do tipo 'gerbox' sobre papel toalha para germinação umedecido com água deionizada na proporção de 2,5 vezes a massa seca do papel (BRASIL, 2009), posteriormente, foram submetidas a estratificação à temperatura de $5^{\circ} \mathrm{C}$ e ausência de luz por 0, 4, 8, 12 e 16 horas.

Após os períodos de estratificação descritos, as sementes foram submetidas ao teste de germinação as quais foram transferidas para caixas plásticas tipo 'gerbox' transparente (luz constante) e escura (ausência de luz), sobre duas folhas de papel toalha para germinação, o qual foi umedecido com água deionizada e solução fungicida de Nistatina (2\%), na proporção de 2,5 vezes a massa do papel (BRASIL, 2009). As sementes foram mantidas em câmara de germinação do tipo B.O.D com luz constante nas temperaturas de $20,25,30$ e $35^{\circ} \mathrm{C}$.

$\mathrm{O}$ delineamento experimental foi inteiramente casualizado em esquema fatorial $5 \times 4 \times 2$, sendo cinco tratamentos pré-germinativos de estratificação $(0$, $4,8,12$ e 16 horas à temperatura de $5^{\circ} \mathrm{C}$ ), quatro temperaturas de germinação $\left(20,25,30\right.$ e $\left.35^{\circ} \mathrm{C}\right)$ e duas condições de luz (luz constante e escuro constante), totalizando 40 tratamentos cada um com 4 repetições de 30 sementes por parcela.

A contagem do número de sementes germinadas foi realizada diariamente durante nove dias, em sala com luz verde de segurança, sendo considerada como germinadas as sementes que apresentaram raiz primária com aproximadamente $2 \mathrm{~mm}$ de comprimento (HADAS, 1976). 
As variáveis analisadas foram a porcentagem de germinação G(\%) (BRASIL, 2009), tempo médio de germinação TMG (dias), segundo Edmond e Drapala (1958), índice de velocidade média de germinação IVG, segundo Silva e Nakagawa (1995), frequência e sincronização da germinação (LABOURIAU; AGUDO, 1987). Todos os dados foram submetidos à análise de variância (teste $\mathrm{F}$ ), sendo as médias comparadas pelo teste Tukey a 5\% de probabilidade. No entanto, vale ressaltar que houve necessidade de transformar os dados do tempo médio de germinação $\sqrt{x+0,5}$ (PIMENTEL, 1990; MISCHAN; PINHO, 1996).

\section{Resultados e Discussão}

As sementes de alface nas temperaturas de 20 e $25^{\circ} \mathrm{C}$ apresentaram maiores porcentagens de germinação (Tabela 1), no entanto, quando foram submetidas à temperatura de $30^{\circ} \mathrm{C}$ houve redução, de aproximadamente 50 pontos percentuais, nessa avaliação. $\mathrm{Na}$ temperatura de $35^{\circ} \mathrm{C}$ a germinação apresentou valores muito baixos independente da presença de luz (Tabela 2). De acordo com Cantliffe, Sung e Nascimento (2000) altas temperaturas $\left(35^{\circ} \mathrm{C}\right)$ podem inibir a germinação de sementes da maioria das cultivares de alface.

Bertagnolli et al. (2003) analisando o desempenho de sementes nuas e peletizadas de alface submetidas aos estresses hídrico e térmico, também concluíram que em temperaturas iguais ou superiores a $25^{\circ} \mathrm{C}$ houve redução na velocidade e porcentagem de germinação e a $35^{\circ} \mathrm{C}$ ocorreu paralisação da germinação das sementes.

Quando as sementes foram estratificadas por 16 horas e posteriormente colocadas a $30^{\circ} \mathrm{C}$ para germinar, houve incremento de 42 pontos percentuais na germinação igualando-se aos resultados das temperaturas de 20 e $25^{\circ} \mathrm{C}$ (Tabela 1). Assim, os resultados indicam que o condicionamento das sementes de alface em ambiente úmido por 16 horas em temperatura de $5^{\circ} \mathrm{C}$, resultou em efeito benéfico na germinação das sementes, mesmo quando estas são, posteriormente, expostas a temperaturas limites de $30^{\circ} \mathrm{C}$.

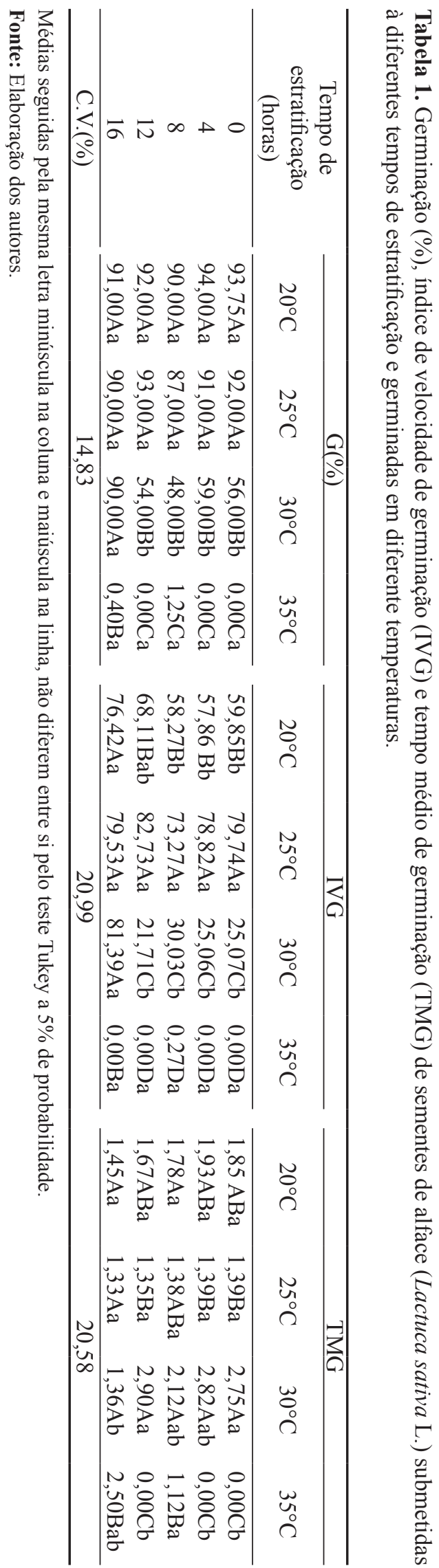


As sementes submetidas à temperatura de $25^{\circ} \mathrm{C}$ apresentaram o maior IVG, independente da condição de luz (Tabela 3), e quando submetidas à estratificação por 16 horas, o IVG (Tabela 1) aumentou tanto para a temperatura de $20^{\circ} \mathrm{C}$ quanto para a temperatura de $30^{\circ} \mathrm{C}$, tornando-as semelhantes ao obtido à $25^{\circ} \mathrm{C}$ (Tabela 1$)$. Além disso, a presença de luz resultou em maior IVG nas temperaturas de 20 e $30^{\circ} \mathrm{C}$ (Tabela 2$)$.
A presença de luz resultou em maior germinação nos tempos de $0,4,8$ e 12 horas de estratificação (Tabela 3), assim como relatado por Flint (1934), Evenari e Neumann (1953) e Toole et al. (1957), conforme citações apresentadas por Labouriau (1983) afirmando que sementes dessa espécie são fotoblásticas positivas.

Tabela 2. Germinação (\%), índice de velocidade de germinação (IVG) e tempo médio de germinação (TMG) de sementes de alface (Lactuca sativa L.) estratificadas e germinadas em diferentes temperaturas e condições de luz.

\begin{tabular}{|c|c|c|c|c|c|c|}
\hline \multirow{2}{*}{ Temperatura $\left({ }^{\circ} \mathrm{C}\right)$} & \multicolumn{2}{|c|}{$\mathrm{G}(\%)$} & \multicolumn{2}{|c|}{ IVG } & \multicolumn{2}{|c|}{ TMG } \\
\hline & Luz & Escuro & Luz & Escuro & Luz & Escuro \\
\hline 20 & $91,00 \mathrm{Aa}$ & $93,00 \mathrm{Aa}$ & $69,24 \mathrm{Ab}$ & $58,96 \mathrm{Bb}$ & $1,62 \mathrm{Ab}$ & $1,85 \mathrm{Aa}$ \\
\hline 25 & $91,00 \mathrm{Aa}$ & $90,00 \mathrm{Aa}$ & $79,14 \mathrm{Aa}$ & $78,49 \mathrm{Aa}$ & $1,38 \mathrm{Ab}$ & $1,35 \mathrm{Aa}$ \\
\hline 30 & $82,00 \mathrm{Ab}$ & $41,00 \mathrm{Bb}$ & $42,47 \mathrm{Ac}$ & $30,84 \mathrm{Bc}$ & $2,94 \mathrm{Aa}$ & $1,84 \mathrm{Ba}$ \\
\hline 35 & $0,33 \mathrm{Ac}$ & $0,33 \mathrm{Ac}$ & $0,06 \mathrm{Ad}$ & $0,08 \mathrm{Ad}$ & $0,25 \mathrm{Ac}$ & $0,40 \mathrm{Ab}$ \\
\hline C.V. $(\%)$ & \multicolumn{2}{|c|}{14,83} & \multicolumn{2}{|c|}{20,99} & \multicolumn{2}{|c|}{20,58} \\
\hline
\end{tabular}

Médias seguidas pela mesma letra minúscula na coluna e maiúscula na linha, não diferem entre si pelo teste Tukey a 5\% de probabilidade. Fonte: Elaboração dos autores.

Tabela 3. Germinação (\%) de sementes de alface (Lactuca sativa L.) submetidas a diferentes tempos de estratificação a $5^{\circ} \mathrm{C}$ e germinadas em condições de luz e escuro.

\begin{tabular}{|c|c|c|}
\hline \multirow{2}{*}{ Tempo de estratificação (horas) } & \multicolumn{2}{|c|}{$G(\%)$} \\
\hline & Luz & Escuro \\
\hline 0 & $65,0 \mathrm{Aa}$ & $56,0 \mathrm{Bb}$ \\
\hline 4 & $66,0 \mathrm{Aa}$ & $56,0 \mathrm{Bb}$ \\
\hline 8 & $65,0 \mathrm{Aa}$ & $47,0 \mathrm{Bb}$ \\
\hline 12 & $67,0 \mathrm{Aa}$ & $53,0 \mathrm{Bb}$ \\
\hline 16 & $67,0 \mathrm{Aa}$ & $68,0 \mathrm{Aa}$ \\
\hline C.V. $(\%)$ & & \\
\hline
\end{tabular}

Médias seguidas pela mesma letra minúscula na coluna e maiúscula na linha, não diferem entre si pelo teste Tukey a 5\% de probabilidade. Fonte: Elaboração dos autores.

A ausência de luz reduziu em 50 pontos percentuais a germinação na temperatura de $30^{\circ} \mathrm{C}$ (Tabela 3). Segundo Menezes et al. (2000) alguns cultivares de alface não germinam se não forem expostas à luz. Esses autores verificaram que nos cultivares de alface, Elisa, Regina e Rainha de Maio, a ausência de luz permitiu uma maior germinação na temperatura de $20^{\circ} \mathrm{C}$ e em temperaturas acima desta houve redução. Além disso, os autores afirmam que as sementes de alface apresentam sensibilidade à luz à medida que a temperatura se eleva, pois na ausência da luz a germinação decresce em temperaturas superiores a $25^{\circ} \mathrm{C}$.

Várias técnicas têm sido propostas para reduzir o tempo necessário entre a semeadura e a emergência das plântulas em sementes de alface, bem como, aumentar a tolerância das sementes às condições adversas existentes nesse período (FESSEL et al., 2002). Assim, no presente trabalho, as sementes estratificadas por 16 horas a $5^{\circ} \mathrm{C}$ resultaram em incremento no IVG, mesmo em condições de temperaturas de $30^{\circ} \mathrm{C}$. 
Mesmo com o melhoramento genético realizado nas cultivares de alface para diminuir a necessidade de luz na germinação dessas sementes, pode-se observar que quando as sementes são submetidas às altas temperaturas $\left(30\right.$ e $\left.35^{\circ} \mathrm{C}\right)$ a presença de luz se torna desnecessária(NASCIMENTO; CANTLIFFE, 2002). No entanto, neste trabalho, no escuro, as sementes estratificadas por 16 horas apresentaram porcentagem de germinação $\mathrm{G}(\%)$ de 68 pontos percentuais e não diferiram estatisticamente das sementes submetidas à presença de luz.

$\mathrm{Na}$ Figura 1 observa-se que a $30^{\circ} \mathrm{C}$ os polígonos de frequência a $0,4,8$ e 12 horas de estratificação apresentaram tendência polimodal na presença de luz, e que, apesar de ter ocorrido germinação, não houve sincronização desse processo. No entanto, na ausência de luz o polígono apresenta tendência unimodal, porém a germinação foi baixa. No tempo de estratificação de 16 horas os polígonos de frequência, tanto na presença, quanto na ausência de luz, apresentaram curva unimodal. Todos os polígonos com tendência unimodal mostraram assimetria negativa (cauda da distribuição para a esquerda), isto implica que a sincronização da germinação das sementes foi concentrada nos primeiros dois dias. Nas temperaturas de 20,25 e $35^{\circ} \mathrm{C}$ não houve diferença na sincronização desse processo.

A frequência de germinação está associada ao índice de sincronização da germinação. Os tempos de estratificação de $0,4,8,12$ e 16 horas não apresentaram diferenças significativas entre si e apresentaram os menores valores para esta variável nas temperaturas de 20 e $25^{\circ} \mathrm{C}$, ou seja, maior sincronização de germinação, enquanto valores nulos foram observados para a temperatura de $35^{\circ} \mathrm{C}$. Na temperatura de $30^{\circ} \mathrm{C}$ houve sincronização apenas quando as sementes passaram pela estratificação por 16 horas (Tabela 4). Já a condição de luz só afetou o índice de sincronização na temperatura de $30^{\circ} \mathrm{C}$ (Tabela 5).

Tabela 4. Índice de sincronização de sementes de alface (Lactuca sativa L.) submetidas a diferentes tempos de estratificação e germinadas em diferentes temperaturas em condições de luz e escuro.

\begin{tabular}{|c|c|c|c|c|c|c|}
\hline \multirow{2}{*}{$\begin{array}{c}\text { Tempo de estratificação } \\
\text { (horas) }\end{array}$} & \multicolumn{6}{|c|}{ Indice de Sincronização } \\
\hline & $20^{\circ} \mathrm{C}$ & $25^{\circ} \mathrm{C}$ & $30^{\circ} \mathrm{C}$ & $35^{\circ} \mathrm{C}$ & Luz & Escuro \\
\hline 0 & $1,11 \mathrm{ABa}$ & $1,02 \mathrm{Ba}$ & $1,52 \mathrm{Aa}$ & $0,00 \mathrm{Ca}$ & $0,96 \mathrm{Aa}$ & $0,86 \mathrm{Aa}$ \\
\hline 4 & $1,15 \mathrm{Aa}$ & $0,98 \mathrm{Aa}$ & 1,33Aab & $0,00 \mathrm{Ba}$ & $1,07 \mathrm{Aa}$ & $0,66 \mathrm{Bab}$ \\
\hline 8 & $1,07 \mathrm{Aa}$ & $1,00 \mathrm{Aa}$ & $1,04 \mathrm{Abc}$ & $0,00 \mathrm{Ba}$ & $1,01 \mathrm{Aa}$ & $0,54 \mathrm{Bb}$ \\
\hline 12 & $1,30 \mathrm{Aa}$ & $0,83 \mathrm{Ba}$ & $1,58 \mathrm{Aa}$ & $0,00 \mathrm{Ca}$ & $1,01 \mathrm{Aa}$ & $0,85 \mathrm{Aab}$ \\
\hline 16 & $1,05 \mathrm{Aa}$ & $0,95 \mathrm{Aa}$ & $0,75 \mathrm{Ac}$ & $0,00 \mathrm{Ba}$ & $0,57 \mathrm{Ab}$ & $0,80 \mathrm{Aab}$ \\
\hline C.V.(\%) & \multicolumn{6}{|c|}{38,96} \\
\hline
\end{tabular}

Médias seguidas pela mesma letra minúscula na coluna e maiúscula na linha, não diferem entre si pelo teste Tukey a $5 \%$ de probabilidade. Fonte: Elaboração dos autores.

Tabela 5. Índice de sincronização de sementes de alface (Lactuca sativa L.) submetidas a diferentes temperaturas de germinação e em condições de luz e escuro.

\begin{tabular}{|c|c|c|}
\hline \multirow{2}{*}{ Temperatura $\left({ }^{\circ} \mathrm{C}\right)$} & \multicolumn{2}{|c|}{ Indice de Sincronização } \\
\hline & Luz & Escuro \\
\hline 20 & $1,21 \mathrm{Ab}$ & $1,06 \mathrm{Aa}$ \\
\hline 25 & $0,95 \mathrm{Ab}$ & $0,96 \mathrm{Aa}$ \\
\hline 30 & $1,54 \mathrm{Aa}$ & $0,95 \mathrm{Ba}$ \\
\hline 35 & $0,00 \mathrm{Ac}$ & $0,00 \mathrm{Ab}$ \\
\hline C.V.(\%) & & \\
\hline
\end{tabular}

Médias seguidas pela mesma letra minúscula na coluna e maiúscula na linha, não diferem entre si pelo teste Tukey a $5 \%$ de probabilidade. Fonte: Elaboração dos autores. 
Figura 1. Frequência relativa da germinação de sementes de alface (Lactuca sativa $\mathrm{L}$.) sob temperatura de $30^{\circ} \mathrm{C}$, em condições de luz e escuro, submetidas a diferentes tempos de estratificação.
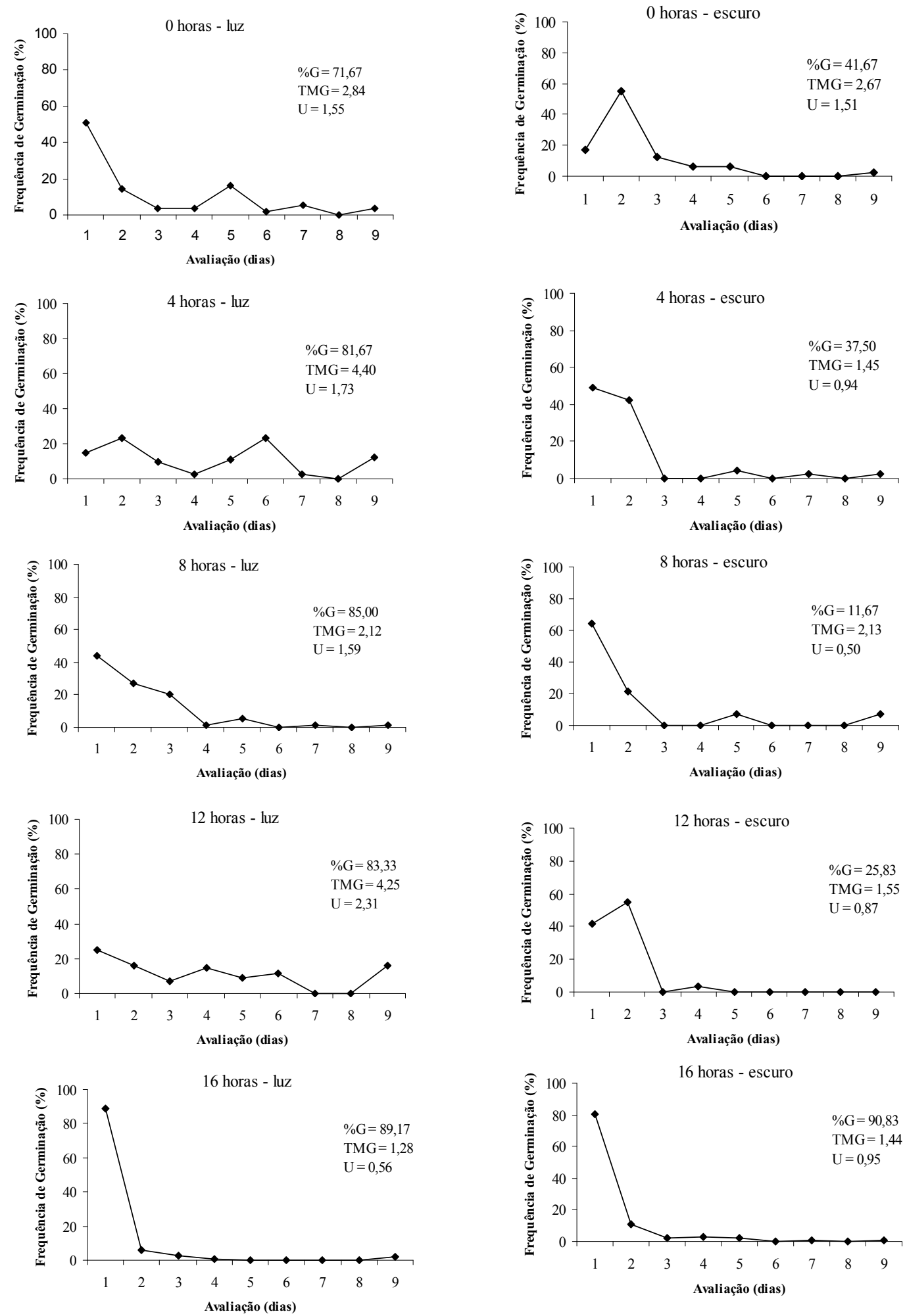

Fonte: Elaboração dos autores. 
Apenas a temperatura de $30^{\circ} \mathrm{C}$ apresentou diferença significativa entre o tempo médio de germinação, sendo que o menor foi obtido com o maior tempo de estratificação. De um modo geral, os menores TMG ocorreram na temperatura de $35^{\circ} \mathrm{C}$ em todos os tempos de estratificação. Já a condição de luz só afetou a temperatura de $30^{\circ} \mathrm{C}$, na qual a ausência de luz levou ao menor TMG (Tabela 3).

A temperatura de $25^{\circ} \mathrm{C}$ promoveu maior $\mathrm{G}(\%)$ e IVG e menor TMG. No entanto, a estratificação de 16 horas estimulou a germinação das sementes de alface, propiciando maior G(\%) e IVG e menor TMG, além de uniformizar a germinação. Sob temperatura de $30^{\circ} \mathrm{C}$, a presença de luz aumentou a G(\%) e reduziu o TMG.

Pode-se inferir que a estratificação alterou o balanço hormonal entre promotores e inibidores da germinação, aumentando o limite de temperatura de germinação das sementes de alface, sugerindo que a estratificação a $5^{\circ} \mathrm{C}$ necessitou de um maior período para reduzir os níveis internos de inibidores da germinação. No trabalho de Tang et al. (2008) a exposição de sementes de Chenopodium album à baixa temperatura aumentou a germinação e segundo os autores, essa indução pode ser devido à síntese de giberelina (GA), uma vez que, a biossíntese de GA é regulada pela luz e temperatura fria. Segundo Yamauchi et al. (2004) durante a biossíntese de GA a reação final é catalisada pelo ácido giberélico 3 oxidase e a expressão dessa enzima é promovida pela estratificação e presença de luz.

Assim, o aumento no acúmulo de frio das sementes de alface pode estar relacionado com a redução no conteúdo de substâncias inibidoras da germinação e com a elevação das substâncias promotoras do mesmo processo. Selim et al. (1998) observaram que durante a estratificação de sementes de pessegueiro a $5^{\circ} \mathrm{C}$, o conteúdo de giberelinas e ácido indolil-acético das sementes aumentaram e o conteúdo de ácido abscísico diminuiu.

O tratamento pré-germinativo de estratificação a $5^{\circ} \mathrm{C}$ por 16 horas estimulou e uniformizou a germinação das sementes e na temperatura de $30^{\circ} \mathrm{C}$, a presença de luz aumentou a germinação e reduziu o tempo médio de germinação. Além disso, os melhores resultados foram obtidos com o maior tempo de estratificação utilizado, sugerindo que tempos maiores de estratificação podem incrementar a germinação de sementes submetidas a altas temperaturas.

\section{Conclusões}

A estratificação por 16 horas e as temperaturas de $20^{\circ} \mathrm{C}$ e $25^{\circ} \mathrm{C}$ estimularam a germinação das sementes de alface, propiciando maior porcentagem de germinação, índice de velocidade de germinação e menor tempo médio de germinação. A presença da luz resultou em maior germinação nos períodos de $0,4,8$ e 12 horas de estratificação.

\section{Referências}

BERTAGNOLLI, C. M.; MENEZES, N. L.; STORK, L.; SANTOS, O. S.; PASQUALLI, L. L. Desempenho de sementes nuas e peletizadas de alface (Lactuca sativa L.) submetidas a estresses hídrico e térmico. Revista Brasileira de Sementes, Londrina, v. 25, n. 1, p. 7-13, 2003.

BLACK, M.; BEWLEY, J. D.; HALMER, P. L - Lettuce. In: BLACK, M.; BEWLEY, J. D.; HALMER, P. (Ed.). The Encyclopedia of seeds. Science, technology and uses. Oxfordshire: CAB International, 2006, p. 377-379.

BOO, H.; HEO, B.; GORINSTEIN, S.; CHON, S. Positive effects of temperature and growth conditions on enzymatic and antioxidant status in lettuce plants. Plant Science, Limerick, v. 4, n. 181, p. 479-484, 2011.

BORTHWICK, H. A.; ROBINS, W. W. Lettuce seed and its germination. Hilgardia, California, v. 3, p. 275-304, 1928.

BRASIL. Ministério da Agricultura, Pecuária e Abastecimento. Regras para análise de sementes. Brasília: SNDA/DNDV/CLAV, 2009. 399 p.

CAMPANA, B.; CAFFARINI, P.; CALVAR, J.; FAITA, E.; PANZARDI, S. Quebra de dormência de sementes de pessegueiro (Prunus persica (L.) Batsch) mediante reguladores de crescimento. Revista Brasileira de Fruticultura, Jaboticabal, v. 15, n. 1, p. 171-176, 1993. 
CANTLIFFE, D. J.; SUNG, Y.; NASCIMENTO, W. M. Lettuce seed germination. Horticultural Reviews, Westport, v. 24, p. 229-275, 2000.

CHALFUN, N. N. J.; HOFFMANN, A. Propagação do pessegueiro. Informe Agropecuário, Belo Horizonte, v. 18, n. 189, p. 23-29, 1997.

COONS, J. M.; KEUHL, R. O.; SIMONS, N. R. Tolerance of ten cultivars to high temperature combined with $\mathrm{NaCl}$ during germination. Journal of the American Society for Horticultural Science, Alexandria, v. 115, n. 6, p. 1004-1007, 1990.

DENG, Z.; SONG, S. Sodium nitroprusside, ferricyanide, nitrite and nitrate decrease the thermo-dormancy of lettuce seed germination in a nitric oxide-dependent manner in light. South African Journal of Botany, Scottsville, v. 78, p. 139-146, 2012.

EDMOND, J. B.; DRAPALLA, W. J. The effects of temperature, sand and soil, and acetone on germination of okra seed. Proceedings of the American Society for Horticultural Science, Alexandria, v. 71, n. 2, p. 428-443, 1958.

FESSEL, S. A.; VIEIRA, R. D.; RODRIGUES, T. J. D.; FAGIOLI, M. Germinação de sementes de alface submetidas a condicionamento osmótico durante o armazenamento. Scientia Agricola, Piracicaba, v. 59, n. 1, p. 73-77, 2002.

FILGUEIRA, F. A. R. Asteráceas - alface e outras hortaliças herbáceas. In: (Ed.). Novo manual de olericultura: agrotecnologia moderna na produção e comercialização de hortaliças. Viçosa: UFV, 2003. p. 289-295.

HADAS, A. Water update germination of leguminous seeds under changing external water potential in osmotic solution. Journal of Experimental Botany, Oxford, v. 27, n. 98, p. 480-489, 1976.

IKUMA, H.; THIMANN, K. V. The role of seed coats in germination of photosensitive Lettuce seeds. Plant Cell Physiology, v. 4, n. 2, p. 169-185, 1963.

WAGNER JUNIOR, A.; SILVA, J. O. da C.; SANTOS, C. E. M. dos; PIMENTEL, L. D. Estratificação de sementes de pessegueiro cv. "Campinas 1", em temperaturas constantes e alternadas. Revista Brasileira Agrociência, Pelotas, v. 13, n. 1, p. 39-42, 2007.

KHAN, A. A. Hormonal regulation of primary and secondary seed dormancy. Israel Journal of Botany, Jerusalém, v. 29, n. 1-4, p. 207-224, 1980/81.
LABOURIAU, L. G. A germinação de sementes. Washington, D.C.: Organização dos Estados Americanos, Programa Regional de Desenvolvimento Científico e Tecnológico, 1983. 174 p. (Biologia Monografia).

LABOURIAU, L. G.; AGUDO, M. On the physiology of seed germination in S.hispanica L. 1. Temperature effects. Anais da Academia Brasileira de Ciências, Rio de Janeiro, v. 59, n. 1, p. 37-56, 1987.

McWHA, J. A. Changes in abscisic acid levels during imbibition and germination of non-dormant and thermotolerant lettuce seeds. Australian Journal of Plant Physiology, v. 3, n. 5, p. 849-851, 1976.

MENEZES, N. L.; SANTOS, O. S.; NUNES, E. P.; SCHMIDT, D. Qualidade fisiológica de sementes de alface submetidas a diferentes temperaturas em presença e ausência de luz. Ciência Rural, Santa Maria, v. 30, n. 6, p. 941-945, 2000.

MISCHAN, M. M.; PINHO, S. Z. de. Experimentação agronômica-dados não balanceados. Botucatu: Fundibio, 1996. 456 p.

NABORS, M. W.; LANG, A. The growth physics and water relations of red-light-induced germination in lettuce seeds. I. Embryos germinating in osmoticum. Planta, Berlin, v. 101, n. 1, p. 1-25, 1971.

NASCIMENTO, W. M. Germinação de sementes de alface. Brasília: Embrapa Hortaliças, dez. 2002. 10 p. (Circular técnica, 29).

NASCIMENTO, W. M.; PEREIRA, R. S. Testes para avaliação do potencial fisiológico de sementes de alface e sua relação com a germinação sob temperaturas adversas. Revista Brasileira de Sementes, Londrina, v. 29, n. 3, p. 175-179, 2007.

NASCIMENTO, W. M.; CANTLIFFE, D. J. Germinação de sementes de alface sob altas temperaturas. Horticultura Brasileira, Campinas, v. 20, n. 1, p. 103-106, 2002.

PIMENTEL, G. Curso de estatística experimental. São Paulo, Nobel, 1990. 468 p.

POPINIGIS, F. Fisiologia da semente. Brasília: AGIPLAN, 1985. 289 p.

SCHEIBE, J.; LANG, A. Lettuce seed germination: Effects of high temperature and repeated far-red treatment in relation to phytochrome. Photochemistry and Photobiology, Malden, v. 9, n. 2, p. 143-150, 1969.

SELIM, H. H.; KILANY, O. A.; ABD-EL-WAHAB, W.; HASSAN, T. Y. Physiological studies on propagation of Nemaguard peach seeds. Arab Universities Journal of Agricultural Sciences, Syrian, v. 6, n. 1, p. 249-266, 1998. 
SILVA, J. B.; NAKAGAWA, J. Estudos de fórmulas para cálculo de velocidade de germinação. Informativo Abrates, Londrina, v. 5, n. 1, p. 62-73, 1995.

SPEER, H. L. Some aspects of the function of the endosperm during the germination of lettuce seeds. Canadian Journal of Botany, Guelph, v. 52, n. 5, p. 11171121, 1974.

TANG, D.; HAMAYUN, M.; KO, Y.; ZHANG, Y.; KANG, S.; LEE, I. Role of red light, temperature, stratification and nitrogen in breaking seed dormancy of Chenopodium album L. Journal of Crop Science and Biotechnology, Korea, v. 11, n. 3, p. 199-204, 2008.
WARREN, J. E.; BENNETT, M. A. Seed hydration using the drum priming system. HortScience, Alexandria, v. 32, n. 7, p. 1220-1221, 1997.

YAMAUCHI, Y.; OGAWA, M.; KUWAHARA, A.; HANADA, A.; KAMIYA, Y.; YAMAGUCHI, S. Activation of gibberellin biosynthesis and response pathways by low temperature during imbibition of Arabidopsis thaliana seeds. Plant Cell, Rockville, v. 16, n. 2, p. 367-378, 2004. 